\title{
Mechanical evaluation of six techniques for stable fixation of the sagittal split osteotomy after counterclockwise mandibular advancement
}

\author{
Leandro Benetti De Oliveira ${ }^{a}$, Jose Mauricio Nunes Reis ${ }^{b}$, Rubens Spin-Neto ${ }^{c}$, \\ Marisa Aparecida Cabrini Gabrielli ${ }^{a}$, Yener Oguz ${ }^{\mathrm{d}, *}$, Valfrido Antonio Pereira-Filho ${ }^{\mathrm{a}}$ \\ ${ }^{a}$ Dental School at Araraquara, Oral and Maxillofacial Surgery Division, São Paulo State University - UNESP, Araraquara, São Paulo, Brazil \\ ${ }^{\mathrm{b}}$ Dental School at Araraquara, Department of Prosthodontics, São Paulo State University - UNESP, Araraquara, São Paulo, Brazil \\ c Section of Oral Radiology, Department of Dentistry, Faculty of Health, Aarhus University, Denmark \\ d Maktoum Bin Hamdan Dental University College, Dubai, United Arab Emirates \\ Accepted 2 March 2016 \\ Available online 7 April 2016
}

\begin{abstract}
We have evaluated the resistance to displacement of six stable methods of fixation of a sagittal split ramus osteotomy (SSRO) in the mandibular advancement with counterclockwise rotation. We tested 60 synthetic hemimandibles in six groups of 10 each: Group I - fixation with a straight four-hole $2.0 \mathrm{~mm}$ miniplate; Group II - a straight six-hole $2.0 \mathrm{~mm}$ miniplate; Group III - two straight $2.0 \mathrm{~mm}$ four-hole miniplates; Group IV - an eight-hole $2.0 \mathrm{~mm}$ (grid plate); Group V - a $2.0 \mathrm{~mm}$ four-hole straight miniplate and $2.0 \times 12 \mathrm{~mm}$ bicortical screw; and Group VI - a straight four-hole $2.0 \mathrm{~mm}$ locking miniplate. We applied a linear force in the region between the canine and the first premolar using a universal testing machine (EMIC- DL2000) with a loading cell of $10 \mathrm{KN}$. The loads at 1, 3, and $5 \mathrm{~mm}$ displacement were recorded (N) and the data transmitted from the load cell to a computer. Results were analysed using analysis of variance (ANOVA) $(p<0.001)$ and the Tukey post-test for comparison of the significance of the differences between the groups. For the three degrees of displacement, fixation with two straight $2.0 \mathrm{~mm}$ plates and with the grid plate gave higher load values.
\end{abstract}

(C) 2016 The British Association of Oral and Maxillofacial Surgeons. Published by Elsevier Ltd. All rights reserved.

Keywords: Rigid internal fixation; Sagittal split ramus osteotomy; Bone plate

\section{Introduction}

The mandibular sagittal split osteotomy is one of the most common operations for the correction of dentofacial deformities that directly or indirectly affect the mandible. ${ }^{1}$ It is versatile because it results in wide contact between the cut

\footnotetext{
* Corresponding author at: Maktoum bin Hamdan Dental University College, Oral Surgery and Implantology Department, Jumeirah 1, Jumeirah Terrace Building, 110, Dubai, United Arab Emirates.

Mobile: +971 501631519; fax: +971 43864474.

E-mail address: yeneroguz@gmail.com (Y. Oguz).
}

segments, which favours healing and stability and allows precise and adequate stable internal fixation. This eliminates the need for intermaxillary fixation, reduces the risk of postoperative aspiration, and facilitates recovery of chewing. It leads to improved oral hygiene and better quality of life for patients during the immediate postoperative period. ${ }^{2}$

Stable fixation of a bilateral sagittal split osteotomy (BSSO) usually involves bicortical screws or miniplates with monocortical screws. Previous studies have shown that fixation with bicortical screws tends to be more rigid and less susceptible to deformation than with a monocortical plate. ${ }^{4,5}$ However, other studies have suggested that there is no 
significant difference between the strength of bicortical fixation and a miniplate with monocortical screws. ${ }^{6,7}$ To maintain the advantages of the miniplates and monocortical screws, and increase the rigidity of fixation, some authors have proposed insertion of a supplementary bicortical screw in the retromolar region. This is known as "the hybrid technique". 8

Currently, the use of the locking miniplate/screw systems is thought to minimise displacement of the segments of bone and improve primary and secondary stability. It also avoids excessive compression of the plate and screw against the cortical bone that could result in localised osteolysis. ${ }^{9}$

BSSO of the mandible with counterclockwise rotation was traditionally considered the least stable treatment and, if the fixation material was not strong enough, early relapse was possible. ${ }^{9}$ To better understand the biomechanics of fixation of a SSO and to improve fixation, experiments are often used to quantify and evaluate it. However, the ideal method has not yet been established. Specifically, we know of few studies on the mechanical evaluation of stable fixation of BSSO for counterclockwise advancement because most studies have focused on mandibular advancement or setback without rotation. 3,11

The aim of this study therefore was to compare the biomechanical stability of six methods of osteosynthesis after BSSO of the mandible for counterclockwise advancement.

\section{Material and Methods}

We used 60 polyurethane replicas of a hemimandible. To obtain standardisation of the BSSO the operation was done on one replica hemimandible using the modification described by Epker. ${ }^{10}$ Sixty, two-segment, polyurethane samples were then produced from that sectioned hemimandible (Nacional Ossos, Jaú, Brazil) for mechanical tests. The experimental specimens were divided into six groups with 10 hemimandibles in each, according to the fixation method used (Fig. 1). The groups are described in Table 1.

The repositioning simulated a mandibular advancement with counterclockwise rotation of the mandible. Acrylic guides were used to standardise repositioning, which measured $8 \mathrm{~mm}$ of advancement at the upper border and $11 \mathrm{~mm}$

Table 1

Details of groups studied ( $\mathrm{n}=10$ in each).

\begin{tabular}{ll}
\hline Group No. & Method of fixation \\
\hline I & $\begin{array}{l}\text { One four-hole (two proximal and two distal) standard } \\
\text { miniplate fixed with standard screws measuring } \\
2.0 \times 6.0 \mathrm{~mm}\end{array}$ \\
& $\begin{array}{l}\text { One six-hole (three proximal and three distal) standard } \\
\text { miniplate fixed with standard screws measuring }\end{array}$ \\
& $2.0 \times 6.0 \mathrm{~mm}$ \\
& Two four-hole (two proximal and two distal) miniplates \\
& fixed with standard screws measuring $2.0 \times 6.0$ mm \\
III & One eight-hole (four proximal and four distal) grid \\
& miniplate fixed with standard screws measuring \\
IV & $2.0 \times 6.0$ mm \\
& Hybrid technique, using one four-hole (two proximal and \\
& two distal) standard miniplate fixed by standard screws and \\
V & $\begin{array}{l}5 \text { mingle } 12 \text { mm bicortical screw on the proximal segment } \\
\text { mandibular border }\end{array}$ \\
& One four-hole (two proximal and two distal) locking \\
& miniplate fixed with locking screws measuring \\
& $2.0 \times 6.0$ mm
\end{tabular}

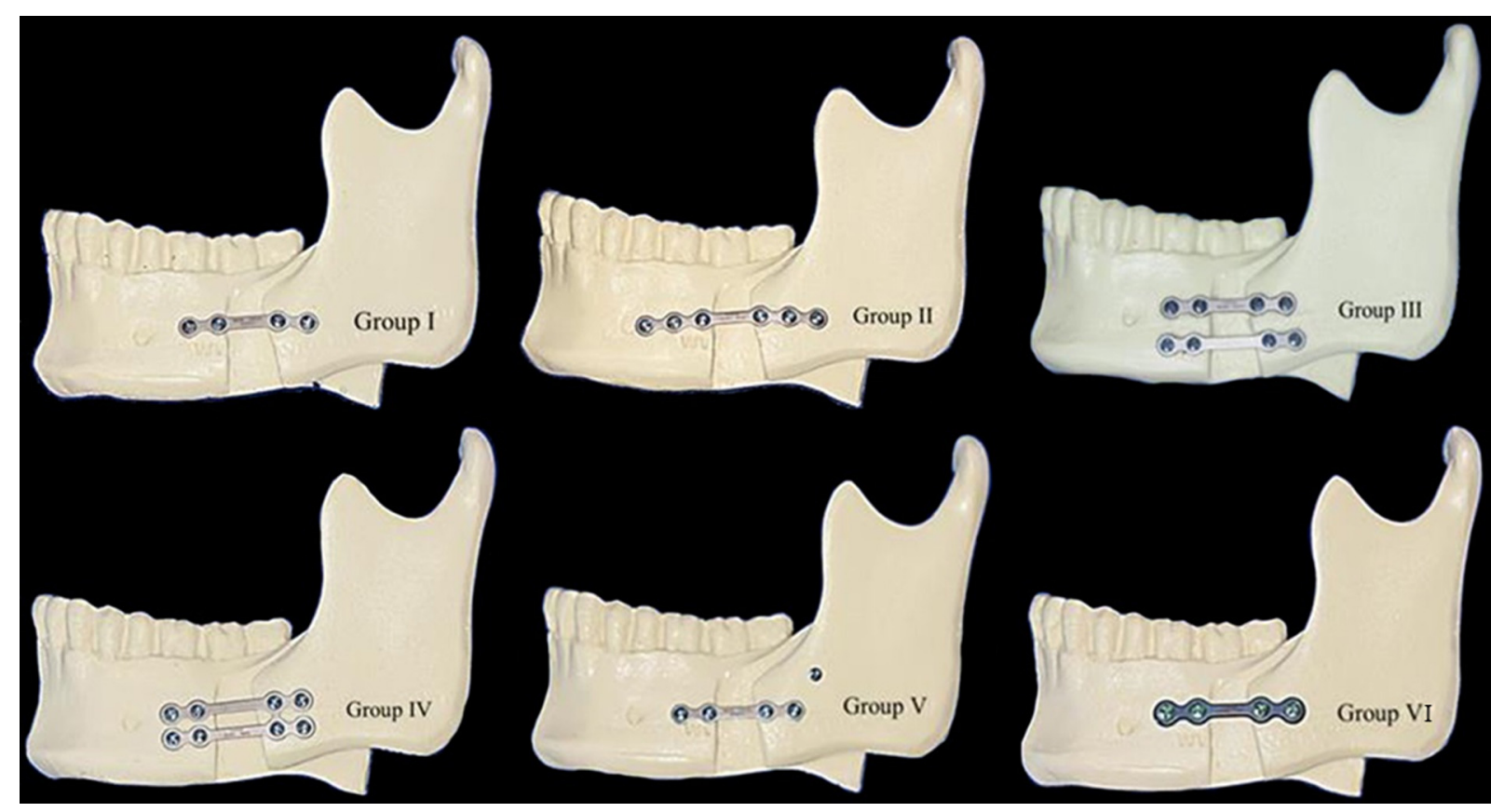

Fig. 1. Experimental design showing different fixation systems in groups I-VI. 
at the lower border of the distal segment. They also guided the placement of miniplates and screws (Fig. 2).

The mechanical testing was based on a cantilever-bending model that was applied to the hemimandibles, and was as described in previous studies that evaluated in vitro mandibular advancement and setback surgery with other types of stable internal fixation devices. ${ }^{11,12}$ For load testing, we used a custom-made support apparatus according to a previous description, in which the proximal segment was rigidly stabilised in the condylar and coronoid areas, but allowed free movement of the distal segment (Fig. 3).

Vertical compression that simulated bite forces was then applied to each sample, as described by Brasileiro et al. ${ }^{3,11}$ The loads were applied between the canine and first premolar by a mechanical test machine (EMIC model DL2000 - Brazil) with a speed of $1 \mathrm{~mm} /$ minute for progressive application of a

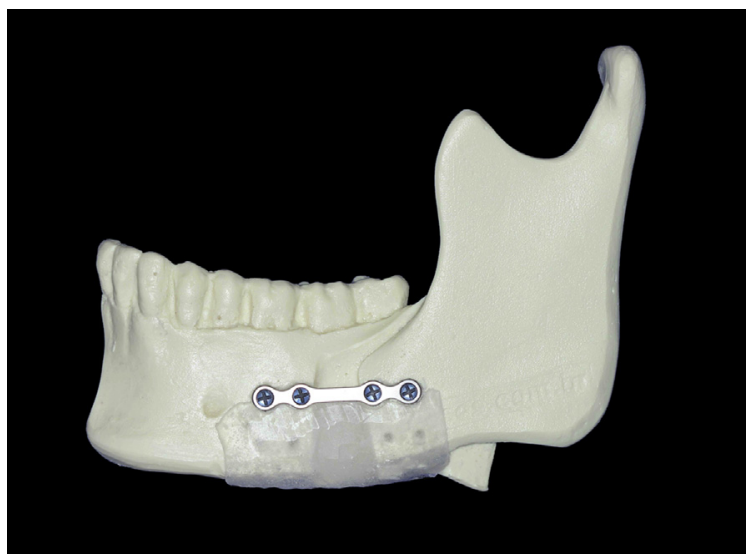

Fig. 2. Acrylic guide splint constructed for each group to standardise the position of each plate.

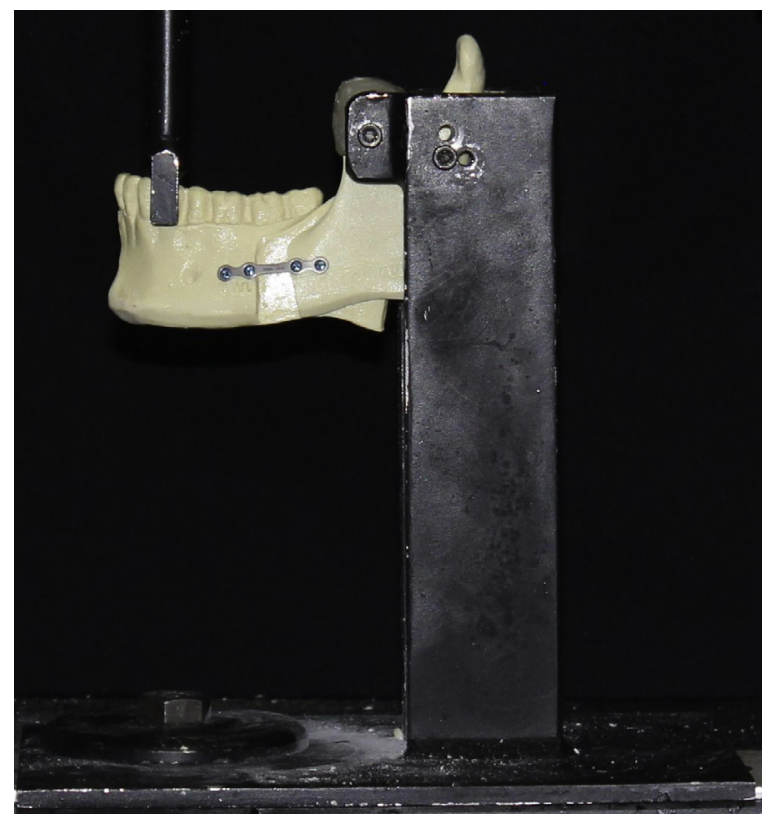

Fig. 3. Custom-made support apparatus with the hemimandible in place ready to start the loading test. load to obtain the load resistance value, measured in Newtons $(\mathrm{N})$. The resistance was measured during the peak load, and allowing for 1,3, and $5 \mathrm{~mm}$ displacements at the fracture site.

\section{Statistical analysis}

Normality of distribution of data was confirmed by the Kolgomorov-Smirnov test. We used a one-way analysis of variance (ANOVA) with a Tukey multiple comparison test to assess the significance of differences between the means within groups and between groups for the same amount of displacement. Probabilities of less than 0.05 were accepted as significant.

\section{Results}

Descriptive results, according to group and displacement, are shown in Table 2, together with measurements within the same group according to the amount of displacement. The greater displacement led to higher load values $(\mathrm{p}<0.001)$.

When the groups were compared for the same amount of displacement, there were three clusters at 1 and $3 \mathrm{~mm}$ : first, the four and six-hole miniplate groups; secondly, the two miniplates and gridplate groups; and thirdly the hybrid and locking groups, always with a highly significant difference $(\mathrm{p}<0.001$ ) between groups (Fig. 4). For $5 \mathrm{~mm}$ displacement the significance of the difference between the locking and two plate groups falls to $p=0.036$, and the differences between the other groups remain at $\mathrm{p}<0.001$.

\section{Discussion}

There is a continuous search for treatments of dentofacial deformity that involve fewer interventions with minimal morbidity and shorter healing, and the method of osteosynthesis is one of the subjects most discussed.

Mechanical testing is one of the most effective ways of evaluating the strength of osteosynthesis, and results may suggest clinical applications. ${ }^{2-5,7,9,11,13}$ To simulate clinical conditions and assess the best fixation technique for SSO, fresh frozen human mandibles ${ }^{7}$ and those from monkeys ${ }^{14}$ and sheep, ${ }^{4}$ as well as fresh porcine ${ }^{15}$ and bovine ribs, ${ }^{16}$ and synthetic models of the human jaw j, $^{3,9,11,12}$ have been used. We used polyurethane hemimandibles because they are easy to obtain, cost little, and allow standardisation.

Various biomechanical studies have used different lengths of movement, varying from 3 to $10 \mathrm{~mm}$, for mandibular advancement. ${ }^{3-5,9,12}$ The reason for simulating the advancement and counterclockwise rotation was to find out whether the change in the angle of the distal segment (and therefore the change in the force transmitted to the plate) would lead to an appreciable difference in primary biomechanical stability.

We did the biomechanical test using a two-point model (cantilevered-beam model), which has been used in 
Table 2

Mean (SD) and range for all groups tested to the loads applied (N).

\begin{tabular}{clllcrc}
\hline & $\begin{array}{l}2.0 \\
\text { four-hole } \\
\text { miniplate }\end{array}$ & $\begin{array}{l}\text { Six-hole } \\
\text { miniplate }\end{array}$ & $\begin{array}{l}\text { Two 2.0 } \\
\text { four-hole } \\
\text { miniplates }\end{array}$ & $\begin{array}{l}\text { Grid } \\
\text { miniplate }\end{array}$ & $\begin{array}{l}\text { 2.0 four-hole } \\
\text { miniplate + bicortical } \\
\text { screw }\end{array}$ & $\begin{array}{l}\text { Four-hole } \\
\text { locking } \\
\text { miniplate }\end{array}$ \\
\hline $1 \mathrm{~mm}:$ & $2.4(0.8)$ & $2.2(0.3)$ & $11.5(1.1)$ & $11.3(1.2)$ & $5.6(0.8)$ & $5.0(0.9)$ \\
Range & $1.8-4.2$ & $1.5-2.7$ & $10.1-13.3$ & $9.7-13.7$ & $4.2-7.5$ & $3.6-7.1$ \\
$3 \mathrm{~mm}:$ & $6.8(1.8)$ & $5.8(1.0)$ & $25.7(2.3)$ & $24.2(2.6)$ & $12.8(2.1)$ & $15.2(3.9)$ \\
Range & $3.9-9.7$ & $4.6-7.6$ & $22.6-28.9$ & $21.0-28.5$ & $8.0-15.3$ & $10.7-22.2$ \\
$5 \mathrm{~mm}:$ & $9.2(2.5)$ & $8.8(0.9)$ & $33.1(4.9)$ & $31.1(4.3)$ & $18.2(2.3)$ & 13.3 \\
Range: & $4.7-13.2$ & $7.3-10.2$ & $25.4-40.7$ & $25.1-41.5$ & $13.3-21.6$ & $15.1-33.5$ \\
\hline
\end{tabular}

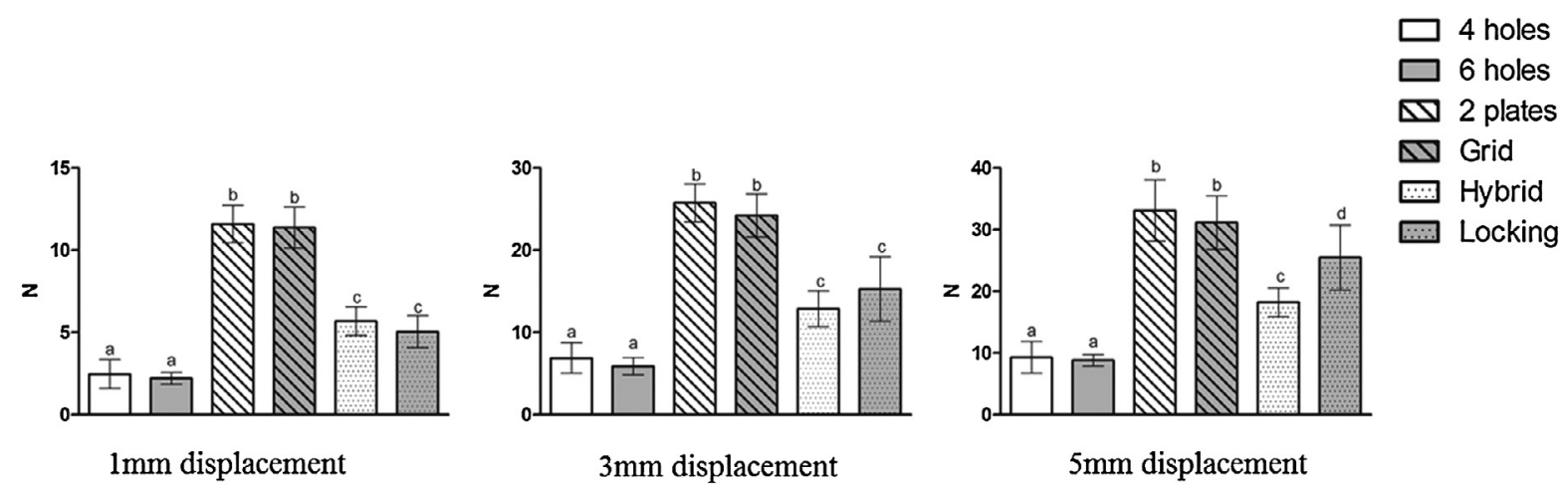

Fig. 4. Results of each group, with their movements, showing the value of the compressive load found.

numerous studies for comparing plate/screw systems. ${ }^{3,5,12}$ Some research workers have pointed out that the weakness of the model is that it does not simulate the masticatory muscles accurately, and suggest the use of a three-point mechanical test. ${ }^{16}$ However, Ribeiro-Junior et al. ${ }^{9}$ suggested that neither two- nor three-point models are accurate substitutes for the evaluation of fixation systems used in mandibular SSO because they do not truly replicate human mandibular function.

Large clinical studies have shown that one miniplate is sufficiently stable for mandibular advancement. ${ }^{4.0,17}$ However, there is a tendency for relapse if repositioning is more than $7 \mathrm{~mm},{ }^{18}$ and in cases of counterclockwise rotation, ${ }^{19}$ which must be taken into consideration. Higher tensions in the soft tissues,and "pulling" of the distal segment into the original position are two causes of relapse. ${ }^{17}$ Some authors have suggested that two parallel miniplates will increase vertical stability in patients with larger movements, or counter clockwise rotation, or both. ${ }^{19}$ Our results showed, however, that for each of the test conditions $(1,3$, and $5 \mathrm{~mm}$ displacement) there was a strong tendency towards higher loads with two straight $2.0 \mathrm{~mm}$ miniplates, followed by the gridplate. Interestingly, there was a minor difference in resistance to displacement between four-hole and six-hole straight plates. The shorter plate is sturdier and more difficult to bend and it creates a shorter lever arm, which increases resistance to displacement.

Currently, the trend for fixation after SSRO is to use miniplates with monocortical screws. However, a hybrid technique, which was first proposed by Schwartz and Relle, ${ }^{20}$ tried to combine the advantages of fixation using bicortical screws with the advantages of fixation using miniplates and monocortical screws. The bicortical screws added to the fixation with a miniplate, and monocortical screws increased the mechanical properties of the fixation systems. ${ }^{3,5,9}$

A biomechanical study by Oguz et al., ${ }^{21}$ compared six methods of fixation after $5 \mathrm{~mm}$ sagittal split advancements. Although the method of the study is similar there is a difference in the resistance to displacement of the different fixation methods when the mandible is rotated counterclockwise. For instance in the first study the hybrid method was a good option for combining resistance and a little increase in the amount of hardware when the mandible was advanced without rotation. Our results show that it seems that when appreciable counterclockwise movements are used, two plates or a grid plate may offer advantages in relation to resistance to displacement, and could be a better option.

Although most in vitro biomechanical studies have verified the advantages of the hybrid technique, Sato et al. ${ }^{22}$ pointed out its disadvantages, including the possibility of torsion at the condylar level, the risk of compression of the alveolar nerve, the need for external incisions in some cases, and the difficulty of removing the bicortical screw in cases of infection or other complications that require removal of the device.

The grid plate that we used varied from the usual design ${ }^{4}$ because it had only one connecting bar, which made it easier to adapt. Despite this altered design, that plate still presented suitable resistance to displacement of the segments of mandibular bone when compared with the other methods 
of fixation. The construct was similar to the use of two miniplates, and the connecting bars in the gridplates may increase resistance to torsional forces. ${ }^{23}$

The locking plate/screw system was first introduced for mandibular reconstruction, and since the development of smaller systems it has also been used for mandibular fractures and SSRO. ${ }^{24}$ It has many theoretical advantages for clinical use such as greater stability, no secondary loss of stability from the screws, less need for precision in the adaptation of the plate, and less alteration in the occlusion. Oguz et al. ${ }^{24}$ compared the stability of the conventional and locking systems on sheep mandibles after SSRO and found mechanical similarities between the two. They also evaluated those materials using a finite element model and found that while the locking plates and screws provided no advantages over conventional miniplates and screws, they spread the load over the plate and screws, thereby reducing the amount of force transferred to each unit. ${ }^{25}$

Ribeiro-Junior et al. ${ }^{9}$ found that the locking plate and screw osteosynthesis systems were better at resisting bone displacement after SSRO, but the results did not differ significantly. We found that the locking plates and screws alone had better biomechanical capabilities than one four-hole or six-hole $2.0 \mathrm{~mm}$ plate. Locking plates and hybrid fixation behaved similarly for the $1 \mathrm{~mm}$ and $3 \mathrm{~mm}$ displacements. There was a significant difference in favour of locking plates for the $5 \mathrm{~mm}$ displacement. At more than $3 \mathrm{~mm}$ displacement the construct has already failed. It seems that locking the screw to the plate increased primary stability more than adding an additional screw, because it made further displacement more difficult.

We conclude that the resistance forces measured at 1, 3, and $5 \mathrm{~mm}$ displacement were higher for two $2.0 \mathrm{~mm}$ plates and the grid plate for advancement with counterclockwise rotation of the mandible.

\section{Conflict of Interest}

We have no conflict of interest.

\section{Ethics Statement/confirmation of patients' permission}

Not required.

\section{References}

1. Borstlap WA, Stoelinga PJW, Hoppenreijs TJ, et al. Stabilization of sagittal split advancement osteotomies with miniplates: a prospective, multicentre study with two-year follow-up. Part III - Condylar remodelling and resorption. Int J Oral Maxillofac Surg 2004;33:649-55.

2. Ochs MW. Bicortical screw stabilization of sagittal split osteotomies. J Oral Maxillofac Surg 2003;61:1477-84
3. Brasileiro BF, Grempel RG, Ambrosano GM, et al. An in vitro evaluation of rigid internal fixation techniques for sagittal split ramus osteotomies: advancement surgery. J Oral Maxillofac Surg 2009;67:809-17.

4. Ozden B, Alkan A, Arici S, et al. In vitro comparison of biomechanical characteristics of sagittal split osteotomy fixation techniques. Int J Oral Maxillofac Surg 2006;35:837-41.

5. Sato FR, Asprino L, Consani S, et al. Comparative biomechanical and photoelastic evaluation of different fixation techniques of sagittal split ramus osteotomy in mandibular advancement. J Oral Maxillofac Surg 2010;68:160-6.

6. Foley WL, Beckman TB. In vitro comparison of screw versus plate fixation in the sagittal split osteotomy. Int J Adult Orthod Orthognath Surg 1992;7:147-51.

7. Tharanon W. Comparison between the rigidity of bicortical screws and a miniplate for fixation of a mandibular setback after a simulated bilateral sagittal split osteotomy. J Oral Maxillofac Surg 1998;56: $1055-8$.

8. Pereira FL, Janson M, SantíAna E. Hybrid fixation in the bilateral sagittal split osteotomy for lower jaw advancement. J Appl Oral Sci 2010;18:92-9.

9. Ribeiro-Junior PD, Magro-Filho O, Sbastri KA, et al. In vitro biomechanical evaluation of the use of conventional and locking miniplate/screw systems for sagittal split ramus osteotomy. J Oral Maxillofac Surg 2010; 68:724-30.

10. Epker BN. Modifications in the sagittal osteotomy of the mandible. $J$ Oral Surg 1977;35:157-9.

11. Brasileiro BF, Grotta-Grempel R, Ambrosano GM, et al. An in vitro evaluation of rigid internal fixation techniques for sagittal spit ramus osteotomies: setback surgery. J Oral Maxillofac Surg 2012;70: 941-51.

12. Pereira Filho VA, Iamashita HY, Monnazzi MS, et al. In vitro biomechanical evaluation of sagittal split osteotomy fixation with a specifically designed miniplate. Int J Oral Maxillofac Surg 2013;42:316-20.

13. Yamashita Y, Mizuashi K, Shigematsu M, et al. Masticatory function and neurosensory disturbance after mandibular correction by bilateral sagittal split ramus osteotomy: a comparison between miniplate and bicortical screw rigid internal fixation. Int J Oral Maxillofac Surg 2007;36: $118-22$.

14. Ellis III E, Reynolds S, Carlson DS. Stability of the mandible following advancement: a comparison of three postsurgical fixation techniques. Am J Orthod Dentofacial Orthop 1988;94:38-49.

15. Foley WL. Appropriate testing of fixation for the mandibular sagittal split osteotomy. J Oral Maxillofac Surg 1994;52:780-1.

16. Armstrong JE, Lapointe HJ, Hogg NJ, et al. Preliminary investigation of the biomechanics of internal fixation of sagittal split osteotomies with miniplates using a newly designed in vitro testing model. $J$ Oral Maxillofac Surg 2001;59:191-5.

17. Borstlap WA, Stoelinga PJ, Hoppenreijs TJ, et al. Stabilisation of sagittal split advancement osteotomies with miniplates: a prospective, multicentre study with two-year follow-up. Part II. Radiographic parameters. Int J Oral Maxillofac Surg 2004;33:535-42.

18. Joss CU, Vassalli IM. Stability after bilateral sagittal split osteotomy advancement surgery with rigid internal fixation: a systematic review. $J$ Oral Maxillofac Surg 2009;67:301-13.

19. Nieblerová J, Foltán R, Hanzelka T, et al. Stability of the miniplate osteosynthesis used for sagittal split osteotomy for closing an anterior open bite: an experimental study in mini-pigs. Int J Oral Maxillofac Surg 2012;41:482-8.

20. Schwartz HC, Relle RJ. Bicortical-monocortical fixation of the sagittal mandibular osteotomy. J Oral Maxillofac Surg 1996;54:234-5.

21. Oguz Y, Watanabe ER, Reis JM, et al. In vitro biomechanical comparison of six different fixation methods following 5-mm sagittal split advancement osteotomies. Int J Oral Maxillofac Surg 2015;44: 984-8.

22. Sato FR, Asprino L, Consani S, et al. A comparative evaluation of the hybrid technique for fixation of the sagittal split ramus osteotomy in mandibular advancement by mechanical, photoelastic, and finite 
element analysis. Oral Surg Oral Med Oral Pathol Oral Radiol 2012;114(5 suppl):s60-8.

23. Peterson GP, Haug RH, Van Sickels J. A biomechanical evaluation of bilateral sagittal ramus osteotomy fixation techniques. J Oral Maxillofac Surg 2005;63:1317-24.

24. Oguz Y, Saglam H, Dolanmaz D, et al. Comparison of stability of $2.0 \mathrm{~mm}$ standard and $2.0 \mathrm{~mm}$ locking miniplate/screws for the fixation of sagittal split ramus osteotomy on sheep mandibles. Br J Oral Maxillofac Surg 2011;49:135-7.

25. Oguz Y, Uckan S, Ozden AU, et al. Stability of locking and conventional 2.0-mm miniplate/screw systems after sagittal split ramus osteotomy: finite element analysis. Oral Surg Oral Med Oral Pathol Oral Radiol Endod 2009;108:174-7. 